electric motors. In this way it is possible to direct the beam of X-rays at will, either through the applicator towards the patient, or into an absorbing lead saddle, six inches thick, suspended immediately above the tube. Thus, the portion of the X-ray tube within the treatment room is both shock-proof and ray-proof.

As the X-ray tube is fixed, the floor of the treatment room has been made movable, so that the position of the patient relative to the tube may be adjusted as desired.

\section{The Generators}

The generating equipment comprises two generators, one designed to give a positive potential of 600,000 volts, and the other a negative potential of the same value (Fig. 2). The current for each generator is fed from the 400 volt A.c. mains into a transformer from which a current at 150,000 volts can be drawn. By means of a modified Greinacher circuit, embodying columns of continuously-evacuated thermionic valves and oil-immersed condensers, a rectified current at a constant potential of 600,000 volts may be obtained from each generator. Thus by using both generators, a constant potential of more than one million volts may be applied to the $\mathrm{X}$-ray tube. At this voltage, the tube is designed to carry a current of five milliamperes.

The $\mathrm{X}$-ray tube and its generating equipment is the culmination of the remarkable series of $\mathrm{X}$-ray installations designed and manufactured during the past few years by the Metropolitan Vickers Electrical Co., Ltd., of Trafford Park, Manchester. The com. pany is to be congratulated on its fine achievement.

The Treasurer and Governors of St. Bartholomew's Hospital, also, should be congratulated on the vision and energy they have displayed in their endeavour to further the conquest of a dread disease. We wish the new department all success in its work.

\title{
Illumination Research at the Science Museum
}

$\mathrm{T}^{\mathrm{H}}$

HE special Exhibition on Electric Illumination being held at the Science Museum (see Nature of December 19, p. 1046) contains a number of research exhibits of considerable interest.

One item from which valuable results may be obtained has been contributed by the National Physical Laboratory and has been designed under the supervision of Dr. J. W. T. Walsh. Two light sources, one a tungsten filament lamp and the other equivalent to the mercury discharge lamp, may be adjusted by the observer until equal brightness appears to be obtained by means of a photometer head. When this has been done, the observer records his observation automatically on a roll of paper, thereby contributing towards the accumulation of mass statistics on popular conceptions of heterochromatic photometry. Practically all observations on this subject have been done hitherto by trained observers. It will be interesting to check whether the untrained observer, some 250,000 of whom will probably visit the exhibition, has substantially the same outlook on the question of equal brightness of differently coloured light sources. A rough check with a small number of completely untrained observers at the National Physical Laboratory revealed considerable disparities compared even with the observations of the less-experienced trained observers. The value of a check test to reveal the disparity range in the visual experiences of the general public may be considerable.

Another experimental device with the object of obtaining mass statistics has been installed by the E.L.M.A. Lighting Service Bureau. Variations in the foot-candle intensity chosen by members of the public for comfort in reading are recorded by a ticket issuing machine which, in addition to delivering a ticket showing the value chosen by the operator, records statistically the sum of its operations. Although 5 foot-candles is an average value of illumination experienced in living rooms, it has been found as a result of 20,000 observations that 70 foot-candles is much nearer the desired value for comfort. Further statistics will be obtained at the Exhibition.
A number of other items in the Exhibition illustrate contemporary research without contributing towards it. One most interesting exhibit projects the arc from a mercury discharge lamp on to a translucent screen, and by means of a stroboscopic disk shows that while the cathode discharge emanates from a hot spot on the cathode, the anode discharge takes place from the surface of the electrode presenting the shortest discharge path to the arc. If both these discharges were to take place from the same spot, disintegration of the electrodes would ensue and the lamp life would be uneconomically curtailed. This device, which has been used extensively by research workers to obtain a proper understanding of the processes involved in sustaining the arc discharge in a hot cathode discharge lamp, is now demonstrated to the public.

The phenomenon of luminescence, discovered by Crookes in 1879 and now applied to electric discharge lamps, is demonstrated by a number of cabinets in which only invisible ultra-violet radiation is allowed to fall on luminescent specimens. The first cabinet shows naturally luminescent minerals. The second shows stages in the preparation of a synthetic luminescent material. Pure zinc sulphide is not luminescent, and does not become so with the addition of an impurity. When, however, the mixture is fired, the resultant product is strongly luminescent. Two further cabinets show the response of some materials to long-wave ultra-violet radiation and others to short-wave ultra-violet, and the fact that a material responding to the one may be unresponsive to the other. A fifth cabinet shows the response of the rhodamines which, strangely enough, respond only in the pure form and then only when in either solid or liquid solution.

The water-cooled high-pressure hot cathode mercury discharge lamp is an example of what is at present a research exhibit, but may before long have important practical applications. The tube is of quartz surrounded by a condenser, and from examination of the spectrum of the discharge it is estimated that a temperature of about $8,000^{\circ}$ C.- approximately that 
of the sun-is reached. The light source is $0.5 \mathrm{~mm}$. diam. $\times 50 \mathrm{~mm}$. long, the pressure 100-200 atmospheres and the power consumption 1,000 watts. An efficiency of $60-70$ lumens per watt is obtained. While the life of these lamps is at present only about 100 hours, the red end of the spectrum of the discharge is about ten times as strong as that of an ordinary street-lighting mercury lamp. The colour rendering of the light obtained is thus far more akin to that obtainable by daylight. Even the commercial highpressure quartz lamp, which will probably be marketed in a few months' time and which works at a pressure of about five atmospheres and a temperature of about $1,000^{\circ} \mathrm{C}$., shows a substantial improvement in the red end of the spectrum. Spectrometer demonstrations of the light from these lamps compared with that from tungsten filament lamps are shown.

\section{Universities of the British Empire}

\section{Fifth Quinquennial Congress}

\begin{abstract}
$A^{\mathrm{T}}$
$T$ the fourth Congress of the Universities of the British Empire in 1931, Sir Donald MacAlister observed that not merely for historical or statistical records, but also for the clear and cogent setting forth of current university problems, and for pertinent and practical suggestions for their solution, it had long been his practice to consult the reports of the Proceedings of these Congresses, and seldom in vain.

The Proceedings of the Fifth Congress, held on July $13-17,1936$ in Cambridge*, in no way fall below the standards established by its predecessors, and suggest that the analysing and Socratic methods of the world's earliest university are alive in the modern world's counterparts of the Academy of Athens. "They say. What say they ? Let them say," is the background of their work and effort-taking toll of the past, working for the present, planning for the future-a readiness to discard the unprofitable, to adapt means to ends and to envisage change.

The Prime Minister in his opening address took his stand on the plane of a lofty idealism which stressed the presence of the spirit of youth, of growth, of vigour, of expansion and of adventure in his own university and the hatred of standardization and mass production-common to all universities; and pleaded for the production of poets like Wordsworth who might inspire Europe and the world with a sense of unity and freedom.
\end{abstract}

On other aspects of the problems confronting universities, Mr. Baldwin was no less insistent. Research workers should be freed from the trammels of too much teaching and relieved from financial anxiety. Communal life is by no means the least important part of the training obtained at universities-a view strongly expressed in the latest report of the University Grants Committee. Universities may have to specialize in certain subjects and arrange for an exchange of students in the event of their being unable to provide for complete instruction in any subject - the latter suggestion recently happily adopted by the Universities of Oxford and Cambridge.

It was appropriate that the Chancellor should be followed by the Vice-Chancellor, who discoursed on some problems which confront universities. $\mathrm{He}$, too, referred to undue specialization and its dangersmaking mention of the arrangement come to with the University of Oxford in respect of the School of Forestry. He had also much that was pertinent to

* Fifth Quinquennial Congress of the Universities of the British Empire, 1936. Report of Proceedings. (Published for the Universities Bureau of the British Empire.) Pp. viii +262 . (London: G. Bell and Bureau of the British Enp.
Sons, I.td., 1936.) 218 . say about training for citizenship-a subject to the discussion of which Sir Ernest Simon made a valuable contribution in his remarks on general, as an alterna. tive to specialized, honours courses, matriculation standards (a question of vital concern to all educational institutions, schools a's well as universities), pass degrees, intensive courses in honours subjects, research, libraries, need for wider exchange and health measures for students.

Following this address, the subject of the provision in Great Britain for post-graduate studies for British and overseas students was introduced by Lord Macmillan, who made an eloquent appeal for the establishment of an institute of legal research. The Vice-Chancellor of the University of London gave a lucid description of what is being done for postgraduate medical education by the British Postgraduate Medical School. Lord Rutherford explained what his department is doing at the Cavendish Laboratory, Cambridge ; and one of his colleagues, Prof. J. A. Ryle, told of the development of research in pure medicine at Cambridge. Lord Nuffield's recent munificent gift to Oxford will enable research to be conducted in other departments of the medical faculty.

The functions of universities in the training of teachers was introduced by Sir T. Percy Nunn. One of the more important and trenchant of his observations was that the universities through their technical departments of education should do more to foster education as a national function. Others spoke on the subject from the point of view of overseas institutions, while the Board of Education, through its chief inspector, suggested certain criticisms of university methods to which full consideration should be given. Among these is the isolation of the teacher's life which, as Prof. Frank Smith of Leeds said, must not constitute what is really a condition of imprisonment.

Dr. H. J. Cody, president of the University of Toronto, delivered an address on the relation of Canadian universities to national life, making par. ticular mention of academic freedom, the importance of the great and inspiring teacher and of physical training.

Two subjects for discussion-careers for university students and physical education in the universitieswere, as was appropriate, concerned with the well. being of those for whom university education is provided. Great Britain is happy in that it has not experienced as yet the effects of a surplus of failed aspirants for university degrees or even of 'failed matrics'. A career for the university graduate is not 